\title{
Patógenos em peixes de ambientes naturais e de cultivo no Estado do Maranhão: Uma visão geral e perspectivas para pesquisa
}

\author{
Pathogens in fish from natural and farmed environments in the State of Maranhão: An overview \\ and perspectives for research \\ Patógenos en peces de ambientes naturales y de cultivo en el Estado de Maranhão: Una visión \\ general y perspectivas para la investigación
}

\section{Resumo}

$\mathrm{Na}$ busca pelo conhecimento sobre sanidade de peixes a compreensão das interações ecológicas é fundamental, mas por um longo tempo houve negligência nos estudos sobre os parasitas que os afetam. Os trabalhos com patógenos de peixes no Estado do Maranhão ainda são insuficientes e por essa razão este trabalho vem com o objetivo de realizar um levantamento de pesquisas científicas desenvolvidas no período de 2010 a 2020 sobre os de patógenos em peixes de ambientes naturais e de cultivo deste estado. Utilizou-se como estratégias metodológicas a busca sistemática por artigos científicos nas plataformas Web of Science, Google Acadêmico, Pubmed, ASFA, Scopus e SciELO, no período compreendido entre 2010 a 2020, com o intuito de reunir informações sobre o tópico em estudo. Os resultados foram separados por categoria de agentes etiológicos pela diversidade de classes e técnicas distintas utilizadas nas pesquisas levantadas. Os dados obtidos evidenciam que os peixes podem ser acometidos por crustáceos ectoparasitas, 
bacterioses, nemátodas, protozoários, mixosporídeos, fungos, monogenóideas e vírus, porém no Maranhão as pesquisas com esses parasitas de peixes ainda são incipientes, neste sentido destaca-se a necessidade de mais estudos sobre sanidade de peixes nesta região. Além disso, estudos detalhados sobre o ciclo de vida dos parasitas e suas vias de transmissão com finalidade de prevenir as infecções, bem como a construção de um plano de ação com estratégias de tratamento, controle e prevenção dessas patologias serão de grande relevância em estudos futuros e ambientalmente sustentáveis.

Palavras-chave: Parasitas; Doenças; Piscicultura; Sanidade.

\begin{abstract}
In the search for knowledge about fish health, understanding ecological interactions is essential, but for a long time there was neglect in studies on parasites that affect them. The work with fish pathogens in the State of Maranhão is still insufficient and for this reason this work comes with the objective of conducting a survey of scientific researches developed in the period from 2010 to 2020 on those of pathogens in fish from natural environments and from cultivation of this state. The systematic search for scientific articles on the Web of Science, Google Scholar, Pubmed, ASFA, Scopus and SciELO platforms was used as methodological strategies, in the period from 2010 to 2020 , in order to gather information on the topic under study. The results were separated by category of etiological agents due to the diversity of classes and different techniques used in the surveys surveyed. The data obtained show that the fish may be affected by ectoparasitic crustaceans, bacterioses, nematodes, protozoa, myxosporids, fungi, monogenoids and viruses, however in Maranhão the research with these fish parasites is still incipient, in this sense the need for more studies on fish health in this region. In addition, detailed studies on the life cycle of parasites and their transmission routes in order to prevent infections, as well as the construction of an action plan with treatment, control and prevention strategies for these pathologies will be of great relevance in future studies and environmentally sustainable. Keywords: Parasites; Diseases; Pisciculture; Sanity.
\end{abstract}

\title{
Resumen
}

En la búsqueda de conocimiento sobre la salud de los peces es fundamental comprender las interacciones ecológicas, pero durante mucho tiempo se descuidó los estudios sobre los parásitos que los afectan. El trabajo con patógenos de peces en el estado de Maranhão es aún insuficiente y por ello este trabajo nace con el objetivo de realizar un relevamiento de las investigaciones científicas desarrolladas en el período de 2010 a 2020 sobre las de patógenos en peces de ambientes naturales y de cultivo. de este estado. Se utilizó como estrategias metodológicas la búsqueda sistemática de artículos científicos en las plataformas Web of Science, Google Scholar, Pubmed, ASFA, Scopus y SciELO, en el período de 2010 a 2020, con el fin de recabar información sobre el tema en estudio. Los resultados fueron separados por categoría de agentes etiológicos debido a la diversidad de clases y diferentes técnicas utilizadas en las encuestas encuestadas. Los datos obtenidos muestran que los peces pueden estar afectados por crustáceos ectoparásitos, bacteriosis, nematodos, protozoos, mixospóridos, hongos, monogenoides y virus, sin embargo, en Maranhão la investigación con estos parásitos de peces es aún incipiente, en este sentido la necesidad de más estudios sobre salud de los peces en esta región. Además, los estudios detallados sobre el ciclo de vida de los parásitos y sus vías de transmisión con el fin de prevenir infecciones, así como la construcción de un plan de acción con estrategias para el tratamiento, control y prevención de estas patologías serán de gran relevancia en futuros estudios y ambientalmente sustentable.

Palabras clave: Parásitos; Enfermedades; Piscicultura; Cordura.

\section{Introdução}

De 2011 a 2018 foi constatado um crescimento de 32,85\% da aquicultura mundial, partindo de 61,8 milhões de toneladas de organismos aquáticos para alcançar 82,1 milhões de toneladas respectivamente. Deste total, a produção de organismos aquáticos em águas interiores representou $62,48 \%$ da cadeia produtiva, e a aquicultura marinha, aproximadamente $37,52 \%$. Em 2018, a produção total de pescado no mundo foi abastecida por $45,99 \%$ proveniente da aquicultura, excluindo-se mamíferos aquáticos, crocodilos, jacarés, algas e outras plantas aquáticas (Souza \& Viana, 2020).

De acordo com a Organização das Nações Unidas para a Alimentação e a Agricultura (FAO, 2019), o Brasil ocupa a $13^{\circ}$ posição no ranking mundial da aquicultura desde o ano de 2013, sendo considerado o segundo maior produtor aquícola do continente americano, tendo destaque à piscicultura continental, a carcinicultura marinha e a malacocultura como os principais ramos da aquicultura brasileira (IBGE, 2020).

Diante deste cenário no país, o estado do Maranhão merece destaque, pois nos últimos anos, acumulou crescimento de $86,34 \%$, partindo de uma produção de 24.150 toneladas de peixes no ano de 2016 para alcançar as 45.000 toneladas em 2019 , 
ganhando posição de destaque na cadeia produtiva nacional (Peixe BR, 2020).

Os peixes nativos dominam o mercado maranhense e desde o ano de 2017 representam mais de $85 \%$ da produção total do estado. Dentre eles, pode-se destacar a produção de tambaqui, que em 2018 alcançou 10.736 toneladas, superando as 10.501 toneladas do ano anterior, além dos seus híbridos tambacu e tambatinga, que tiveram produção em 2018 de 9.284 toneladas (IBGE, 2020).

Para alcançar tais números, novas técnicas com ciclos de produção cada vez mais reduzidos têm sido desenvolvidas no mundo inteiro, e junto com elas, inúmeros problemas vem aparecendo, principalmente os que dizem respeito a sanidade e bem-estar animal (Brito et al., 2019), devido ao desequilíbrio da tríade patógeno-hospedeiro-ambiente.

A existência de fatores predisponentes (estresse, variação brusca na temperatura da água, excesso de amônia, alta densidade de estocagem, baixa qualidade de água, entre outros) aliado à introdução de patógenos em uma propriedade livre pode ocasionar um impacto devastador na criação, com morbi-mortalidade elevada, podendo dizimar a criação (Leira et al., 2017a).

Diversos são os grupos de agentes etiológicos que apresentam importância na produção e comercialização de peixes e na saúde pública. Entre os principais grupos destacam-se os dinoflagelados, protozoários, mixosporídeos, monogenéticos, nematóides e os crustáceos, além de fungos, bactérias e vírus que, ao encontrarem condições adequadas, proliferam causando as doenças (Tavechio, Guidelli \& Portz, 2018).

Os peixes são hospedeiros ideais para uma grande variedade de parasitas, por isso o desenvolvimento e aprimoramento de técnicas de pesquisa para observação, extração e identificação aliadas ao manuseio prático e a facilidade de acesso a instrumentos de baixo custo contribui para o desenvolvimento da ciência e possibilita descrever melhor o perfil epidemiológico e avaliação do risco de se adquirir zoonoses (Ferraz et al., 2014).

Dessa forma, o objetivo deste trabalho foi realizar levantamento de pesquisas científicas realizadas no período de 2010 a 2020 acerca de patógenos em peixes do estado do Maranhão.

\section{Metodologia}

O presente trabalho é classificado quanto aos fins em pesquisa exploratória por ter sido desenvolvida com o objetivo de proporcionar uma visão geral acerca da temática e maior familiaridade com a mesma. Quanto à natureza do método em pesquisa quali-quantitativa e do ponto de vista dos procedimentos técnicos adotados, em pesquisa bibliográfica.

A pesquisa bibliográfica envolveu o levantamento de informações referentes aos anos de 2010 a 2020, o que representa informações referentes aos patógenos em peixes. Dessa forma, foi realizada uma busca nos bancos de dados do Web of Science, Google Acadêmico, Pubmed, ASFA, Scopus e SciELO, com os descritores diferentes dependendo dos patógenos abordados, da seguinte forma: (i) bacterioses os unitermos "aeromonas", "flavobacterium", "flexibacter", "yersinia", "edwardsiella"; (ii) monogenóides os termos "monogenea", "monogenea"; (iii) crustáceos ectoparasitos os unitermos “isópodes", “ectoparasitas", "braquiúros", “argulus", "dolops", "Perulernaea”; (iv) para fungos "doenças fúngicas", "fungo”, "piscicultura", "saprolegnia"; (v) nematóides "nematoda"; (vi) protozoários "protozoa"; e, (vii) vírus os termos "vírus", "doenças". Independentes do patógeno pesquisado foram associadas às palavras + "fish" + "Maranhão" para limitar a área de estudo.

Os critérios utilizados para seleção das pesquisas foram a abordagem do tema pesquisado restrito ao estado do Maranhão, artigo completo, publicados nos idiomas português, inglês ou espanhol, no período de 2010 a 2020.3

Foram obtidos 65 artigos sobre bacterioses, 116 sobre monogenea, 45 sobre fungos, 13 sobre crustáceos ectoparasitas, um sobre protozoários, dois sobre mixosporídeos, 50 sobre os nematóides e cinco sobre vírus, onde por meio dos critérios empregados no levantamento bibliográfico, e após a leitura do título e resumo para enquadramento da área geográfica 
escolhida, foram selecionados 29 trabalhos (oito de bacterioses, três de monogeneas, dez de fungos, três de nematódeos, um de protozoários, dois de mixosporídeos, nove de ectoparasitas crustáceos e três de vírus); em seguida, este número foi reduzido a 12 (quatro de bacterioses, três de monogeneas, um de fungos, dois de nematódeos, um de protozoários, dois de mixosporídeos), a partir dos critérios de exclusão do trabalho.

\section{Resultados e Discussão}

Os resultados foram separados por categoria de agentes etiológicos pela diversidade de classes e técnicas distintas utilizadas nas pesquisas levantadas, sendo resumidos na Tabela 1 abaixo.

Tabela 1. Relação de agentes etiológicos, hospedeiros e métodos utilizados para identificação de trabalhos desenvolvidos no estado do Maranhão no período de 2010 a 2020.

\begin{tabular}{|c|c|c|c|}
\hline Agente etiológico & Hospedeiro & Método utilizado & Referência \\
\hline Aeromonas hydrophila & $\begin{array}{l}\text { Peixe Serra } \\
\text { Scomberomerus } \\
\text { brasiliensis }\end{array}$ & $\begin{array}{c}\text { Metodologia convencional (cultura + } \\
\text { identificação bioquímica) }\end{array}$ & $\begin{array}{l}\text { Ferreira et al. } \\
\qquad(2014)\end{array}$ \\
\hline $\begin{array}{c}\text { Aeromonas cavie; } \text { A. } \\
\text { hydrophila e Salmonella spp. }\end{array}$ & $\begin{array}{c}\text { Traíra } \\
\text { Hoplias malabaricus }\end{array}$ & $\begin{array}{c}\text { Metodologia convencional (cultura + } \\
\text { identificação bioquímica) }\end{array}$ & $\begin{array}{l}\text { Guimarães et al. } \\
\text { (2017) }\end{array}$ \\
\hline Aeromonas spp. & $\begin{array}{c}\text { Tambaqui } \\
\text { Colossoma } \\
\text { macropomum }\end{array}$ & $\begin{array}{c}\text { Metodologia convencional (cultura + } \\
\text { identificação bioquímica) }\end{array}$ & $\begin{array}{l}\text { Santos et al. } \\
\text { (2019) }\end{array}$ \\
\hline Aeromonas hydrophila & $\begin{array}{l}\text { Pescada Amarela } \\
\text { Cynoscion acoupa }\end{array}$ & $\begin{array}{c}\text { Metodologia convencional (cultura }+ \\
\text { identificação bioquímica) }\end{array}$ & Lopes et al. (2012) \\
\hline $\begin{array}{l}\text { Gyrodactylus spp. } \\
\text { Dactylogyrus spp. }\end{array}$ & $\begin{array}{l}\text { Traíra } \\
\text { H. malabaricus }\end{array}$ & $\begin{array}{c}\text { Metodologia convencional (identificação } \\
\text { morfológica) }\end{array}$ & $\begin{array}{l}\text { Rodrigues et al. } \\
\qquad \text { (2017) }\end{array}$ \\
\hline $\begin{array}{l}\text { Urocleidoides bulbophallus } \mathrm{n} . \\
\qquad \mathrm{sp} \text {; }\end{array}$ & & & \\
\hline $\begin{array}{c}\text { Urocleidoides brasiliensis; } \\
\text { U. cuiabai; } \\
\text { U. malabaricusi } \mathrm{e} \\
\text { Constrictoanchoratus } \mathrm{n} \text {. gen. }\end{array}$ & $\begin{array}{l}\text { Traíra } \\
\text { H. malabaricus }\end{array}$ & $\begin{array}{c}\text { Metodologia convencional (identificação } \\
\text { morfológica) }\end{array}$ & $\begin{array}{l}\text { Ferreira et al. } \\
\qquad(2017)\end{array}$ \\
\hline $\begin{array}{c}\text { Cosmetocleithrum berecae; } \\
\text { Demidospermus osteomystax } \\
\mathrm{e} \\
\text { D. tocantinensis }\end{array}$ & $\begin{array}{l}\text { Auchenipterus } \\
\text { nuchalis }\end{array}$ & $\begin{array}{c}\text { Metodologia convencional (identificação } \\
\text { morfológica) }\end{array}$ & $\begin{array}{l}\text { Cohen et al. } \\
\quad(2020)\end{array}$ \\
\hline $\begin{array}{l}\text { Acremonium sp., Rizopus sp., } \\
\text { Mucor } \text { sp., Aspergillus sp., }\end{array}$ & $\begin{array}{l}\text { Tilápia } \\
\text { Tilápia rendali }\end{array}$ & & \\
\hline $\begin{array}{c}\text { Penicillium sp., } \\
\text { Fusarium sp., Trichoderma } \\
\text { sp., Saprolegnia } \mathrm{sp.}\end{array}$ & $\begin{array}{c}\text { Tambaqui } \\
\text { Colossoma } \\
\text { macropomum }\end{array}$ & $\begin{array}{c}\text { Metodologia convencional (cultura + } \\
\text { identificação morfológica) }\end{array}$ & $\begin{array}{l}\text { Pinheiro et al. } \\
\qquad(2015)\end{array}$ \\
\hline $\begin{array}{l}\text { Contracaecum spp., } \\
\text { Pseudoterranova spp., } \\
\text { Eustrongylides spp. }\end{array}$ & $\begin{array}{c}\text { Traíra } \\
\text { Hoplias malabaricus }\end{array}$ & $\begin{array}{c}\text { Metodologia convencional (identificação } \\
\text { morfológica) }\end{array}$ & $\begin{array}{l}\text { Rodrigues et al. } \\
\qquad \text { (2017) }\end{array}$ \\
\hline $\begin{array}{c}\text { Nematoda Rudolphi, } \\
\text { Secernentea Linstow, } \\
\text { Oxyuroidea Cobbold, } \\
\text { Pharyngodonidae Travassos, } \\
\text { Ichthyouris Inglis; } \\
\text { Ichthyouris nunani n. sp. }\end{array}$ & $\begin{array}{c}\text { Piau-vara } \\
\text { Laemolyta taeniata; } \\
\text { Curimatá } \\
\text { Curimata acutirostris }\end{array}$ & $\begin{array}{c}\text { Metodologia convencional (identificação } \\
\text { morfológica) }\end{array}$ & $\begin{array}{l}\text { Cárdenas et al. } \\
\qquad(2019)\end{array}$ \\
\hline $\begin{array}{l}\text { Calyptospora gonzaguensis } \mathrm{n} . \\
\text { sp. }\end{array}$ & $\begin{array}{c}\text { Sardinha } \\
\text { Triportheus angulatus } \\
\end{array}$ & Caracterização morfológica e molecular & Silva et al. (2020a) \\
\hline
\end{tabular}




\begin{tabular}{cccc}
\hline Myxobolus sp. & Lambari & & \\
& $\begin{array}{c}\text { Astyanax aff. } \\
\text { bimaculatus }\end{array}$ & Caracterização morfológica e molecular & Silva et al. (2019) \\
Ceratomyxa fonsecai n. sp. & $\begin{array}{l}\text { Jatuarana } \\
\text { Hemiodus } \\
\text { unimaculatus }\end{array}$ & Caracterização morfológica e molecular & $\begin{array}{c}\text { Silva } \text { et al. } \\
(2020 \mathrm{~b})\end{array}$ \\
\hline
\end{tabular}

Fonte: Autores (2020).

\section{Crustáceos Ectoparasitos}

Entre os vários grupos de parasitas de peixes de água doce, os crustáceos podem ser apontados como um dos grupos que causam maior perda econômica às pisciculturas. Para Pavanelli, Takemoto e Eiras (2015), as perdas causadas por parasitas e outros patógenos são de cunho econômico podendo incorrer na falência do empreendimento.

De acordo com Pazdiora et al. (2020) o parasitismo por crustáceos conhecidos popularmente como "vermes-âncora" é um grave problema para peixes dulciaquícolas. Para os mesmos pesquisadores, a espécie Perulernaea gamitanae causa considerável dano aos tecidos dos peixes parasitados. Segundo Jerônimo et al. (2012) a Perulernaea, se fixa na boca e nas brânquias por meio de ganchos em formato de âncora localizados na cabeça do parasito.

Segundo Pazdiora et al. (2020) os estudos referentes à sanidade na piscicultura são incipientes, principalmente de doenças parasitárias, tanto sobre agentes causais, agentes predisponentes e aspectos patológicos, quanto ao desenvolvimento de protocolos que estabeleçam a infecção experimental dos principais parasitos que acometem as espécies piscícolas. Apesar da sua importância, no estado do Maranhão até o momento não foram publicados trabalhos com ectoparasitos.

\section{Bacterioses}

A maior parte das bactérias que possuem importância econômica na piscicultura é considerada como micro-organismo oportunista, que podem ser encontrados na microbiota dos peixes ou estarem presentes na água sem necessariamente desencadear uma enfermidade (Leira et al., 2017b). Em condições adversas, resultado normalmente de manejo inadequado ou qualidade de água insatisfatória, estes microrganismos podem desencadear sérios problemas no sistema produtivo.

Embora existam inúmeras bactérias que infectam peixes, algumas delas merecem destaque pela frequência de ocorrências em diversas regiões do país, destacando-se as Aeromonas móveis, Edwardsiella spp., Salmonella spp., Flavobacterium columnare e Streptococcus agalactiae (Leira et al., 2016).

Destes microrganismos mencionados, no estado do Maranhão, da Silva Lopes et al. (2012) relataram a presença de Aeromonas hydrophila em 45,24\% das amostras de pescada amarela, Cynoscion acoupa desembarcadas em São Luís. Ferreira et al. (2014) relataram A. hydrophila em 15\% das amostras de peixe serra, Scomberomerus brasiliensis, desembarcados no município de Raposa. Guimarães et al. (2017) também relataram a ocorrência das espécies A. cavie e A. hydrophila em 90\% dos peixes analisados, além de Salmonella spp. em 5\% das amostras de traíra, Hoplias malabaricus, provenientes de feiras livres do município de São Bento. E mais recentemente, Santos et al. (2019) relataram a presença de Aeromonas spp. em 93,3\% dos tambaquis, Colossoma macropomum provenientes de feiras públicas e supermercados do município de São Luís.

Todos os trabalhos isolando bactérias de peixes provenientes do Maranhão utilizaram apenas metodologias convencionais para isolamento e identificação (série bioquímica), de acordo com as técnicas descritas pela American Public Health Association (Apha, 2001), ou utilizando autores como Havelaar \& Vonk (1988); Majeed, Egan \& Macera (1990).

Estes métodos microbiológicos são amplamente empregados, por outro lado, o tempo de isolamento e a padronização dos resultados bioquímicos podem se tornar entraves (Silva et al., 2014). Por estes motivos, o diagnóstico molecular tem ganhado espaço, e dentre as ferramentas utilizadas pode-se destacar a reação em cadeia da polimerase - PCR (Santos et al., 
2001) e as técnicas de Polimorfismo de Fragmento de Restrição Lento (RFLP Restriction Fragment Length Polymorphism) do 16S rDNA (Borrell et al., 1997).

Já existem protocolos descritos para diagnóstico de micro-organismos utilizando a PCR (Carvalho-Castro et al., 2010, Oliveira, Veneroni-Gouveia \& Costa, 2012; Tsai et al., 2012). Onde se pode destacar a metodologia proposta por Ye et al. (2013) que além da amplificação de genes de virulência, ainda consideram o sequenciamento da região 16S rDNA, que pode ser utilizada para a identificação de várias espécies do gênero, além da análise de similaridade entre as linhagens.

Os testes moleculares foram considerados mais específicos do que o método convencional utilizado para identificação de Aeromonas spp. como descrito por Beaz-Hidalgo et al. (2010) e Silva et al. (2014), que relataram inconsistências na identificação dessa mesma espécie, quando comparados os métodos convencionais e moleculares.

\section{Nematoda}

Os nematoides são parasitos comuns nos peixes de água doce e a maioria das espécies necessita de um hospedeiro intermediário para completar seu desenvolvimento. A maioria dos nematodas registrados em peixes pertence às famílias Pharyngodonidae, Cucullanidae, Camallanidae e Anisakidae (Pavanelli, Takemoto \& Eiras, 2015).

Para coleta, fixação das espécies de parasitas utilizam-se normalmente os métodos descritos por Eiras, Takemoto \& Pavanelli (2006) e quantificação dos parasitos Tavares-Dias, Martins e Moraes (2001). A identificação se dá por meio de literaturas existentes, como por exemplo, Moravec (2001) e Thatcher (1991; 2006).

Dentre os trabalhos realizados no estado do Maranhão destacam-se o de Rodrigues et al. (2017) e o de Cárdenas et al. (2019). Rodrigues et al. (2017) pesquisaram os aspectos parasitológicos da Traíra, Hoplias malabaricus (Bloch 1794) provenientes da Baixada Maranhense. Os nematódeos obtidos nas amostras de H. malabaricus foram do gênero Contracaecum spp., Pseudoterranova spp., Eustrongylides spp. As traíras parasitadas apresentaram larvas no mesentério, com exceção de um exemplar que estava inserido na bexiga natatória. Após a identificação, a conservação dos nematóides foi feita em álcool $70^{\circ}$ GL com $5-10 \%$ de glicerina.

Cárdenas et al. (2019) capturaram os espécimes de Laemolyta taeniata (Kner, 1858) (Piau-vara) e de Curimata acutirostris Vari e Reis, 1995 (Curimatá) no Rio Tocantins, estado do Maranhão. Os peixes adquiridos foram examinados para parasitas imediatamente após a captura. Nos espécimes analisados foram observadas e identificadas as seguintes espécies de parasitas: Nematoda Rudolphi, 1808 Secernentea Linstow, 1905 Oxyurida Chabaud, 1974 Oxyuroidea Cobbold, 1864 Pharyngodonidae Travassos, 1919 Ichthyouris Inglis, 1962 Ichthyouris nunani n. sp.

As enfermidades de peixes com caráter zoonótico devem ser alvo de preocupação, requerendo um maior controle por parte de serviços de fiscalização diminuindo, assim, as taxas de morbidade e mortalidade nas criações, garantindo a obtenção do pescado de boa qualidade, já que os parasitas podem infectar todas as partes dos peixes. As informações a respeito dos nematoides em peixes ainda são escassas no estado do Maranhão.

\section{Protozoários}

O filo Protozoa reúne diversos organismos evolutivamente distintos que podem atuar como ecto ou endoparasitos de peixes em todo o mundo, sendo responsáveis por doenças as quais, por sua vez, podem ocasionar impactos econômico e social nos diferentes países. Apesar dos recentes avanços no campo de diagnóstico de doenças em peixes no Brasil, ainda pouco se conhece sobre a fauna de protozoários parasitos de peixes e suas relações com o ambiente e hospedeiro (Martins et al. 2015).

Os protozoários parasitos de peixes de maior importância zoonótica, pertencem aos filos Ciliophora (Tricodina spp., Ichthyophthirius multifilis e Epistylis spp.) e Miozoa (Piscinoodinium sp.) (Martins et al., 2001; Pádua et al., 2011; Ishikawa et al., 2016). 
Apesar da importância zoonótica dos protozoários para os peixes, estudos sobre o grupo no Maranhão, são escassos. Apenas um trabalho foi publicado recentemente sobre protozoários no estado, onde Silva et al. (2020a), estudaram a coccidiose hepática em Triportheus angulatus (Spix \& Agassiz, 1829) e descreveram uma nova espécie de Calyptospora (Apicomplexa: Calyptosporidae) na região de Imperatriz, Maranhão. O trabalho foi desenvolvido no Laboratório de Limnologia e Ecologia da Universidade Estadual da Região Tocantina do Maranhão (LEL/UEMASUL).

Para identificação dos parasitas, foram utilizados protocolos de histologia (Casal et al., 2007) e análises moleculares como a PCR (Whipps et al., 2012; Dogga et al., 2015; Matos et al., 2018).

\section{Mixosporídeos}

O filo Myxozoa (mixosporídeos) constitui-se em um grupo de parasitas abundante e diverso, comumente encontrado em peixes teleósteos (Acosta et al., 2016). Os principais mixosporídeos causadores de doenças em peixes são os pertencentes aos gêneros Henneguya e Myxobolus (Eiras, 2004).

No Maranhão, foram realizados dois estudos sobre organismos mixosporídeos. Silva et al., (2019), identificaram o gênero Myxobolus em brânquias de Astyanax aff. bimaculatus na Bacia do Rio Tocantins, provenientes do município de Governador Edson Lobão e o trabalho de Silva et al. (2020b), que descreveram Estreito e Imperatriz, Maranhão. As amostras de mixozoários de ambos os trabalhos foram coletados e fixados na solução de Davidson para histologia (Videira et al., 2016) e etanol $80 \%$ para estudo molecular.

As análises morfométricas, histológicas e moleculares seguiram as metodologias adaptadas por Gunter et al. (2009), Kaur et al. (2016); Whipps et al. (2003); Diamant et al. (2004) e Adriano e Okamura (2017).

\section{Fungos}

Os peixes mantidos em elevada densidade de estocagem em pisciculturas, quando em produção intensa, inclina ao estresse e a imunossupressão. Essa condição favorece a ocorrência de infecções, entre elas, a saprolegniose, cujo agente etiológico é o oomiceto aquático Saprolegnia sp. Podem ocorrer em ovos, larvas, alevinos além de peixes adultos, o que leva ao desenvolvimento de micélio branco ou cinza claro na pele seguida da multiplicação e elongação das hifas (filamentos) formando os típicos "tufos de algodão", podendo ocorrer perda de escamas. Ocorre também nas brânquias, facilmente visíveis a olho nú (Stueland, Hatai \& Skaar 2005; Lopes 2012).

Não existem na literatura, informações suficientes acerca da importância das doenças e perdas causadas por fungos na piscicultura brasileira, tanto em animais de produção como ornamentais. Nesse cenário, o trabalho de Pinheiro et al. (2015) que avaliaram a qualidade da água e a incidência de fungos em peixes oriundos de pisciculturas do município de São Luís, Maranhão, foi um dos pioneiros no tema. Os exemplares de peixes coletados tiveram as brânquias e a pele removidas para o isolamento de prováveis lesões, onde foram identificadas oito espécies pertencentes aos gêneros Acremonium, Rizopus, Mucor, Aspergillus, Penicillium, Fusarium, Trichoderma, e um gênero importante economicamente para a piscicultura, o oomiceto Saprolegnia.

A metodologia utilizada para identificação de fungos nos peixes, as brânquias e a pele foram retiradas com o auxílio de tesoura, pinça e lâminas esterilizadas. Em seguida, colocadas em sacos plásticos esterilizados e conduzidas para realizar o isolamento e identificação dos fungos.

A técnica utilizada foi o isolamento em placa contendo meio de cultura batata-dextrose-ágar (BDA), conforme metodologia utilizada por Menezes e Assis (2004) e, em seguida, incubados a $25 \pm 2^{\circ} \mathrm{C}$, em alternância luminosa (12h de claro/ $12 \mathrm{~h}$ de escuro).

As colônias dos fungos foram codificadas e as culturas puras preservadas em tubos de ensaio, contendo BDA, em 
refrigeração à $5^{\circ} \mathrm{C}$. $\mathrm{Na}$ identificação foram considerados os principais gêneros fúngicos presentes no isolamento e foram utilizadas lâminas e lamínulas na preparação das amostras. A visualização das estruturas fúngicas foi realizada em microscópio óptico de acordo com metodologias propostas por Singh et al., (1991) e Barnett e Hunter (1972).

\section{Monogenoidea}

Entre os parasitos que infectam peixes, os Monogenoidea constituem um grupo que desempenha papel importante como patógenos devido ao fato de que afetarem órgãos e tecidos que são vitais ao funcionamento normal: as brânquias e a superfície do corpo. Segundo a World Organisation for Animal Health (www.oie.int), a infecção em peixes causada por Gyrodactylus salaris, um ectoparasita vivíparo de água doce da Família Gyrodactylidae e Classe Monogenea, é o único agente patogênico deste grupo com notificação obrigatória. Esta espécie tem distribuição restrita à Europa sendo observados no salmão do Atlântico ou truta arco-íris selvagens ou de viveiro (Johnsen \& Jensen, 1986; Paladini et al., 2009; Rokicka, Lumme \& Zietara, 2007; Zietara et al., 2007).

A detecção e identificação de parasitos monogenéticos é um processo que geralmente ocorre em duas etapas. Primeiramente os espécimes são observados por meio de um estereomicroscópio (lupa), posteriormente são identificados individualmente usando outros equipamentos e métodos. Para a identificação molecular da espécie, os pesquisadores em geral utilizam o marcador mitocondrial citocromo oxidase 1 (CO1) (Hansen, Bachmann \& Bakke, 2003; Hansen, Bachmann \& Bakke, 2007; Meinilä et al., 2004).

No Maranhão, Rodrigues et al. (2017) observaram monogenoideos em Hoplias malabaricus (Bloch 1794), comumente conhecido como "traíra", obtidos de pescadores locais da cidade de São Bento e Ferreira et al. (2017) identificaram espécies monogenoideas também na espécie Hoplias malabaricus capturados no Rio Gurupi. Adicionalmente, Cohen et al. (2020) registraram a presença de monogenoideos em peixes da espécie Auchenipterus nuchalis (Spix \& Agassiz 1829), popularmente conhecidos como "mapará", capturados no Rio Tocantins. Os três trabalhos citados realizaram a identificação das espécies de parasitos utilizando descrição morfológica com auxílio do microscópio óptico. Cohen et al. (2020) e Ferreira et al. (2017) detalham a identificação taxonômica com o uso do corante Tricromo de Gomori para visualização dos órgãos internos e o meio de Hoyer para estudo das estruturas esclerotizadas.

\section{Vírus}

Segundo Essbauer e Ahne (2001) mais de 125 vírus foram identificados em peixes, com identificação por meio de técnicas moleculares. As famílias Alloherpesviridae (DNA), Iridoviridae (DNA), Poxviridae (DNA), Nodaviridae e Rhabdoviridae (RNA) hospedam várias espécies que causam doenças em peixes com altas taxas de morbidade e mortalidade (Gotesman et al., 2013; Whittington, Becker \& Dennis, 2010; Yong et al., 2017).

Maganha et al. (2019) realizaram um estudo em São Paulo (Brasil) com 100 espécimes de peixes ornamentais de 24 espécies diferentes e identificaram o Megalocytivirus (Maganha et al., 2018). Outro estudo realizado pelos mesmos autores identificou Lymphocystivirus a partir de um teste realizado com 25 espécimes de peixes ornamentais brasileiros (Maganha et al., 2019).

Em ambos os estudos o método utilizado em laboratório para diagnosticar as patologias virais foi o molecular. No primeiro trabalho as espécies de peixes foram testadas por PCR para Megalocytivirus, com uma taxa de positividade de $47 \%$. A reconstrução filogenética, baseada no gene da proteína do capsídeo principal (MCP), agrupou todas as amostras em um único clado, que mostrou valores de identidade que variam de $99 \%$ a $100 \%$ quando comparados entre si. Os autores constataram infecção por Megalocytivirus em algumas espécies de peixes ornamentais no Brasil (Maganha et al., 2018). No estudo realizado por Maganha et al. (2019) com a utilização de diagnóstico molecular foi detectado apenas uma amostra 
positiva e seu nucleotídeo viral foi agrupada com sequências do genótipo VII. Este trabalho diferencia-se por ser o primeiro a fazer a caracterização genética de Lymphocystivirus no Brasil. No entanto, apesar de sua importância não há relatos de estudos de diagnósticos de doenças virais em peixes no estado do Maranhão.

Das classes de patógenos abordadas, não foram encontrados trabalhos de ectoparasitos e vírus no estado do Maranhão para o período estudado. No entanto, dentre os trabalhos de bactérias, nematóides, fungos, protozoários, myxosporídeos e monogenóides, foi possível perceber que em 76,92\% dos trabalhos realizados no estado do Maranhão utilizam apenas técnicas convencionais para identificação dos patógenos, onde os estudos com protozoário e myxosporídeos foram os únicos a associar as técnicas de rotina (identificação morfológica) com achados moleculares.

Estes dados deste trabalho reforçam a necessidade de estudos sobre a biologia, ecologia, patologia e cuidados que se deve ter com agentes patogênicos de peixes em cultivos e em seus ambientes naturais para descobrir até que ponto as condições do meio são propícias para o desenvolvimento desses agentes.

\section{Considerações Finais}

De acordo com tudo que foi descrito acerca dos patógenos de peixes, concluímos que são inúmeros os agentes causadores de patologias em peixes, dentre eles destaca-se vírus, bactérias, protozoárias, fungos, helmintos, moluscos e crustáceos, todos eles com capacidade de desencadear sérios problemas econômicos aos empreendedores do ramo da piscicultura, contaminações nos ambientes naturais dos peixes e mortalidade das espécies ícticas. Este trabalho de revisão sistemática evidencia que pesquisas realizadas com sanidade de peixes no estado do Maranhão ainda são incipientes, o que gera uma enorme lacuna científica a ser preenchida. Ainda são necessários estudos detalhados do ciclo dos parasitas, e as suas vias de transmissão, com a construção de um plano de ação direcionado às estratégias para tratamento, controle e prevenção destas patologias em peixes cultivados de água doce, com ações ambientalmente corretas, garantindo a produção e sua sustentabilidade econômica.

\section{Referências}

Acosta, A. A., Godoy, A. T., Yamada, F. H., Brandão, H., Paes, J. V. H., Bongiovani, M. F., Müller, M. I., Yamada, P. O. F., Narciso, R. B., \& Silva, R. J. (2016). Aspectos parasitológicos dos peixes. In R. J. Silva (Org.), Integridade ambiental da represa de Jurumirim: ictiofauna e relações ecológicas. Editora UNESP, pp. 115-192.

Adriano, E. A., \& Okamura, B. (2017). Motility, morphology and phylogeny of the plasmodial worm, Ceratomyxa vermiformis n. sp. (Cnidaria: Myxozoa: Myxosporea). Parasitology, 144(2), 158-168.

American Public Health Association - APHA. (2001). Compendium of Methods for the Microbiological Examination of Foods (4a ed.). APHA, 676p.

Barnett, H. L., \& Hunter, B. B. (1972). Illustrated genera of imperfect fungi. Burgess Publishing Company, 241p.

Beaz-Hidalgo, R., Alperi, A., Buján, N., Romalde, J. L., \& Figueras, M. J. (2010). Comparison of phenotypical and genetic identification of Aeromonas strains isolated from diseased fish. Systematic and Applied Microbiology, 33(3), 149-153. https://doi.org/10.1016/j.syapm.2010.02.002.

Borrell, N., Acinas, S. G., Figueras, M. J., \& Martínez-Marcia, A. J. (1997). Identification of Aeromonas clinical isolates by restriction fragment length polymorphism of PCRamplified 16S rRNA genes. Journal of Clinical Microbiology, 35(7), 1671-1674. https://doi.org/10.1128/JCM.35.7.1671-1674.1997.

Brito, J. M., Ferreira, A. H. C., Santana Júnior, H. A., Oliveira, A. P. A., Santos, C. H. L., \& Oliveira, L. T. S. (2019). Desempenho zootécnico de juvenis de tilápias do nilo (Oreochromis niloticus) alimentados com cepas probióticas e submetidos a desafio sanitário. Ciência Animal Brasileira. 20, 1-9. https://doi.org/10.1590/1809-6891v20e-37348.

Cárdenas, M. Q., Fernandes, B. M. M., \& Justo, M. C. N. (2019). A New Species of Ichthyouris inglis, 1968 (Nematoda: Pharyngodonidae) Parasitizing Two Characiform Fishes from Tocantins River, Maranhão State, Brazil. Comparative Parasitology, 86(1), 5-9.

Carvalho-Castro, G. A., Lopes, C. O., Leal, C. A. G., Cardoso, P. G., Leite, R. C., \& Figueiredo, H. C. P. (2010). Detection of type III secretion system genes in Aeromonas hydrophila and their relationship with virulence in nile tilapia. Veterinary microbiology, 144(3), 371-376. https://doi.org/10.1016/j.vetmic.2010.01.021.

Casal, G., Padovan, I., Matos, E., \& Padovan, P. (2007). Morphological and ultrastructural redescription of Calyptospora serrasalmi Cheung, Nigrelli \& Ruggieri, 1986 (Apicomplexa: Calyptosporidae), a parasite found in two new host species of the genus Serrasalmus. Brazilian Journal Morphology Science, $24,11-16$. 
Cohen, S. C., Justo, M. C. N., Gen, D. V. S., \& Boeger, W. A. (2020). Dactylogyridae (Monogenoidea, Polyonchoinea) from the gills of Auchenipterus nuchalis (Siluriformes, Auchenipteridae) from the Tocantins River, Brazil. Parasite, 27(4), 1-12. https://doi.org/10.1051/parasite/2020002.

Diamant, A., Whipps, C. M., \& Kent, M. L. (2004). A new species of Sphaeromyxa (Myxosporea: Sphaeromyxina: Sphaeromyxidae) in devil firefish, Pterois miles (Scorpaenidae), from the northern Red Sea: morphology, ultrastructure, and phylogeny. Journal of Parasitology, 90, 1434-1442.

Dogga S. K., Bartošová-Sojková, P., Lukeš, J., \& Soldati-Favre, D. (2015). Phylogeny, morphology, and metabolic and invasive capabilities of epicellular fish coccidium Goussia janae. Protist, 166(6), 659-676. https://doi.org/10.1016/j.protis.2015.09.003.

Eiras, J. C. (2004). Aspectos Gerais da Patologia das Parasitoses de Peixes Marinhos. In M. J. T. Ranzani-Paiva, R. M. Takemoto, \& M. A. P. Lizama, Sanidade de Organismos Aquáticos. Varela, 143-156p.

Eiras, J. C., Takemoto, R. M., \& Pavanelli, G. C. (2006). Métodos de estudo e técnicas laboratoriais em parasitologia de peixes (2a ed.). Eduem. 199 pp.

Essbauer, S., \& Ahne, W. (2001). Viruses of lower vertebrates. Journal of Veterinary Medicine, 48(6), 403-75.

FAO. Food and Agriculture Organization of the United Nations. (2019). Yearbook Fishery and Aquaculture Statistics 2017/FAO annuaire. 108 p. http://www.fao.org/3/ca5495t/CA5495T.pdf.

Ferraz, R. R. N., Namba, T. K., Nigro, C. A., Rodrigues, F. S. M., Fornari, J. V., \& Barnabé, A. S. (2014). Comparação entre os métodos de extração de metacercárias de Ascocotyle sp (Trematoda: Digenea) dos tecidos de Mugil liza Valenciennes, 1836 (Teleostei: Mugilidae). Ciência animal brasileira, 15(3), 354-361.

Ferreira, E. M., Lopes, I. S., Pereira, D. M., Rodrigues, L. C., \& Costa, F. N. (2014). Qualidade microbiológica do peixe serra (Scomberomerus brasiliensis) e do gelo utilizado na sua conservação. Arquivos do Instituto Biológico, 81(1), 49-54. http://dx.doi.org/10.1590/S1808-16572014000100009.

Ferreira, K. D. C., Rodrigues, A. R. O., Cunha, J. M., \& Domingues, M. V. (2017). Dactylogyrids (Platyhelminthes, Monogenoidea) from the gills of Hoplias malabaricus (Characiformes: Erythrinidae) from coastal rivers of the Oriental Amazon Basin: species of Urocleidoides and Constrictoanchoratus n. gen. Journal of Helminthology, 92(3), 353-368. https://doi.org/10.1017/S0022149X17000384.

Gotesman, M., Kattlun, J., Bergmann, S. M., \& El-Matbouli, M. (2013). CyHV-3: the third Cyprinid herpesvirus. Diseases of Aquatic Organisms, 105(2), 16374.

Guimarães, L., Santos, A. C., Ferreira, E., Pereira, D., \& Costa, F. (2017). Microbiological quality of trahira fish (Hoplias malabaricus) from Baixada Maranhense, municipality of São Bento, MA. Arquivos do Instituto Biológico, 84, 1-7, eX142015. https://doi.org/10.1590/1808-165700x142015.

Gunter, N. L., Whipps, C. M., \& Adlard, R. D. (2009). Ceratomyxa (Myxozoa: Bivalvulida): robust taxon or genus of convenience? International Journal for Parasitology, 39, 1395-1405.

Hansen, H., Bachmann, L., \& Bakke, T. A. (2003). Variação do DNA mitocondrial de Gyrodactylus spp. (Monogenea, Gyrodactylidae) populações infectando salmão do Atlântico, grayling e truta arco-íris na Noruega e na Suécia. International Journal for Parasitology, 33, 1471-1478.

Hansen, H., Bakke, T. A., \& Bachmann, L. (2007). Diversidade de haplótipos mitocondriais de Gyrodactylus thymalli (Platyhelminthes; Monogenea): a amostragem geográfica estendida no Reino Unido, Polônia e Noruega revela outras linhagens. Parasitology Research, 100(6), 1389-1394.

Havelaar, A. H., \& Vonk, M. (1988). The preparation of ampicillin dextrin Ágar for the enumeration of Aeromonas in water. Letters in Applied Microbiology, 7(6), 169-171.

IBGE. Instituto Brasileiro de Geografia e Estatística. (2020). Produção da pecuária municipal (v.45). https://www.ibge.gov.br/estatisticas/economicas/agricultura-e-pecuaria/9107-producao-da-pecuaria-municipal.html?=\&t=o-que-e.

Jerônimo, G. T., Tavares-Dias, M., Martins, M. L., \& Ishikawa, M. M. (2012). Manual para coleta de parasitos em peixes de cultivo (E-book). Embrapa, 38p. https://www.embrapa.br/busca-de-publicacoes/-/publicacao/935222/coleta-de-parasitos-em-peixes-de-cultivo.

Johnsen, B. O., \& Jensen, A. J. (1986). Infestations of Atlantic salmon, Salmo salar, by Gyrodactylus salaris in Norwegian rivers. Journal of Fish Biology, 29(2), 233-241.

Kaur, H., Attri, R., \& Joshi, J. (2016). Molecular identification of a new myxozoan, Myxobolus dermiscalis n. sp. (Myxosporea) infecting scales of Labeo rohita Hamilton in Harike Wetland, Punjab (India). International Journal for Parasitology Wildl, 5, 139-144.

Leira, M. H., Lago, A. A., Viana, J. A., Cunha, L. T., Mendonça, F. G., \& Freitas, R. T. F. (2017ª). As principais doenças na criação de tilápias no Brasil: revisão de literatura. Nutritime Revista Eletrônica, 14(2), 4982-4996.

Leira, M. H., Assis Lago, A., Botelho, H. A., Melo, C. C. V., Mendonça, F. G., Nascimento, A. F., \& Freitas, R. T. F. (2016). Principais infecções bacterianas na criação de peixes de água doce do Brasil - Uma Revisão. Revista de Ciência Veterinária e Saúde Pública,3(1), 44-59. https://doi.org/10.4025/revcivet.v3i1.32436.

Leira, M. H., Reghim, L. S., Ciacci, L. S., Cunha, L. T., Botelho, H. A., Braz, M. S., Pereira Dias, N., \& Melo, C. C. V. (2017b). Problemas sanitários das pisciculturas brasileiras. PUBVET, 11(6), 538-544.

Lopes, I. S., Ferreira, E. M., Pereira, D. M., Pereira, L. S., Cunha, M. C. S., \& Costa, F. N. (2012). Pescada amarela (Cynoscion acoupa) desembarcada: características microbiológicas e qualidade do gelo utilizado na sua conservação. Revista do Instituto Adolfo Lutz, 71(4), 677-684.

Lopes, J. C. (2012). Técnico em agropecuária: piscicultura. EDUFPI, 80 p. http://pronatec.ifpr.edu.br/wp-content/uploads/2013/06/Piscicultura.pdf. 
Lucca Maganha, S. R. D., Cardoso, P. H. M., De Carvalho Balian, S., Almeida-Queiroz, S. R., Fernandes, A. M., \& Sousa, R. L. M. (2019). Detection and molecular characterization of Lymphocystivirus in Brazilian ornamental fish. Brazilian Journal of Microbiology, 51(2), 53-535.

Lucca Maganha, S. R. D., Cardoso, P. H. M., De Carvalho Balian, S., Almeida-Queiroz, S. R., Fernandes, A. M., \& Sousa, R. L. M. (2018). Molecular detection and phylogenetic analysis of megalocytivirus in Brazilian ornamental fish. Archives of virology, 163(8), $2225-2231$.

Maganha, S. R. D.; Cardoso, P. H. M.; Balian, S. D.; De Almeida-queiroz, S. R.; Fernandes, A. M.; De Sousa, R. L. M. (2019). Detection and molecular characterization of Lymphocystivirus in Brazilian ornamental fish. Brazilian Journal of microbiology. 51 (2), 53-535.

Maganha, S. R. D.; Cardoso, P. H. M.; Balian, S. D.; De Almeida-queiroz, S. R.; Fernandes, A. M.; De Sousa, R. L. M. (2018). Molecular detection and phylogenetic analysis of megalocytivirus in Brazilian ornamental fish. Archives of virology, (163)8, 2225-2231

Majeed, K. N., Egan, A. F., \& Macera, I. C. (1990). Production of exotoxins by Aeromonas spp. at $5^{\circ}$ C. Journal of Applied Microbiology, $69,332-337$.

Martins, M. L., Cardoso, L., Marchiori, N., \& Pádua, S. B. (2015). Protozoan infections in farmed fish from Brazil: diagnosis and pathogenesis. Brazilian Journal of Veterinary Parasitology, 24(1), 1-20.

Martins, M. L., Moraes, J. R. E., Andrade, P. M., Schalch, S. H. C., \& Moraes, F. R. (2001). Piscinoodinium pillulare (Schäperclaus 1954) Lom, 1981 (Dinoflagellida) infection in cultivated freshwater fish from Northeast region of São Paulo State, Brazil. Parasitological and pathological aspects. Brazilian Journal of Biology, 61(4), 639-644.

Matos, P. S., Silva, D. T., Hamoy, I., \& Matos, E. (2018). Morphological features and molecular phylogeny of Hoferellus azevedoi n. sp. (Myxozoa: Myxobilatidae) found in Chaetobranchus flavescens Heckel, 1840 (Teleostei: Cichlidae) from Marajo Island, northern Brazil. Parasitology Research, 117(4), 1087-1093.

Menezes, M., \& Assis, S. M. P. (2004). Guia prático para fungos fitopatogênicos. Impressa Universitária, 183 p.

Meinilä, M., Kuuselaa, J., Zietara, M. S., \& Lummea, J. (2004). Initial steps of speciation by geographic isolation and host switch in salmonid pathogen Gyrodactylus salaris (Monogenea: Gyrodactylidae). International Journal for Parasitology, 34(4), 515-526.

Oliveira, S. T. L., Veneroni-Gouveia, G., \& Costa, M. M. (2012). Molecular characterization of virulence factors in Aeromonas hydrophila obtained from fish. Pesquisa Veterinária Brasileira, 32(8), 701-706.

Pádua, S. B., Martins, M. L., Varandas, D. M., Dias Neto, J., Ishikawa, M. M., \& Pilarski, F. (2011). Tricodinídeos: quem são e o que podem causar nos peixes. Panorama da Aquicultura, 21(127), 22-29.

Paladini, G., Ustinelli, A., Fioravanti, M. L., Hansen, H., \& Shinn, A. P. (2009). The first report of Gyrodactylus salaris Malmberg, 1957 (Platyhelminthes, Monogenea) on Italian cultured stocks of rainbow trout (Oncorhynchus mykiss Walbaum). Veterinary Parasitolology, 165(3-4), $290-297$.

Pavanelli, G. C., Takemoto, R. M., \& Eiras, J. C. (2015). Parasitologia de peixes de água doce do Brasil. Eduem, 452p.

Pazdiora, B. R. C. N., Souza, R. H. B., Medeiros, S. P., Oliveira, W. I., Silva, E. E., \& Holanda, N. G. M. (2020). Evaluation of the development of the life cycle of the parasite Perulernaea gamitanae under in vitro and in vivo culture conditions. Brazilian Jounal of Development, 6(2), 8907-8921.

PEIXEBR. Associação Brasileira da Piscicultura (2020). Anuário PeixeBR da Piscicultura. Edição Texto Comunicação Corporativa. https://www.peixebr.com.br/anuario-2020/.

Pinheiro, C. A. M., Pinheiro, R. S., Santos, W. H. L., Serra, I. M. R. S., \& Santos, D. M. S. (2015). Qualidade da água e incidência de fungos em peixes oriundos de pisciculturas do município de São Luís, Maranhão. Pesquisa em Foco, 20(1), 53-59.

Rodrigues, L. C., Santos, A. C. G., Ferreira, E. M., Teófilo, T. F., Pereira, D. M., \& Costa, F. N. (2017). Aspectos parasitológicos da traíra (Hoplias malabaricus) proveniente da cidade de São Bento, MA. Arquivo Brasileiro de Medicina Veterinária e Zootecnia, 69(1), 264-268.

Rokicka, M., Lumme, J., \& Zietara, M. (2007). Identificação de ectoparasitas Gyrodactylus em fazendas de salmonídeos poloneses por PCR-RFLP do segmento ITS nuclear do DNA ribossomal (Monogenea, Gyrodactylidae). Acta Parasitologica, 52, 185-195.

Santos, E. J. R., Galeno, L. S., Bastos, L. S., Costa, T. F., Carvalho, I. F., \& Costa, F. N. (2019). Qualidade higiênico-sanitária de tambaqui (Colossoma macropomum) comercializado na cidade de São Luís - MA. Ciência Animal Brasileira, 20(1-12), e-46537.

Santos, L. R., Nascimento, V. P., Oliveira, S. D., Flores, M. L., Pontes, A. A., Pilotto, F., Neves, N., Salle, C. T. P., \& Lopes, R. F. F. (2001). Identificação de Salmonella através da reação em cadeia pela polimerase (PCR). Arquivos Faculdade de Veterinária UFRGS, 29(2), 87-92.

Silva, M. F., Orlanda, J. F. F., Araújo-Costa, M. J., Hamoy, I., \& Matos, E. (2020a). Hepatic Coccidiosis in Triportheus angulatus Spix \& Agassiz, 1829 (Characiformes: Triportheidae), a Tropical Fish from the Eastern Brazilian Amazon, with the Description of a New Species of Calyptospora (Apicomplexa: Calyptosporidae). Journal of Eukaryotic Microbiology, 67(3), 352-358.

Silva, M. F., Sousa-Henrique, D. D., Messias-Luz, N., Borralho, L. S., Oliveira, J. D., Sedeaux-Neto, J. L., \& Matos, E. R. (2019). Myxobolus sp. (Myxozoa; Myxosporea) causing asymptomatic parasitic gill disease in Astyanax aff. bimaculatus (Characiformes; Characidae) in the Tocantins river basin, amazon region, Brazil. Brazilian Journal of Veterinary Parasitology, 28(4), 739-743.

Silva, M. F., Carvalho, A. E. F. B., Hamoy, I., \& Matos, E. (2020b). Coelozoic parasite of the family Ceratomyxidae (Myxozoa, Bivalvulida) described from motile vermiform plasmodia found in Hemiodus unimaculatus Bloch, 1794. Parasitology Research, 119, 871-878.

Silva, A. C. M. M., Nascimento, D. L., Machado, R. Z., \& Costa, F. N. (2014). Caracterização de Aeromonas spp isoladas de amostras de ostras e água por métodos microbiológico e molecular. Ciência Animal Brasileira, 15(3), 362-368. 
Singh, K., Danmarks Tekniske Højskole., \& Frøpatologisk Institut for Udviklingslandene. (1991). An illustrated manual on identification of some seed-borne Aspergilli, Fusaria, Penicillia and their mycotoxins. Hellerup: Danish Government Institute of Seed Pathology and Department of Biotechnology, 133p.

Souza, A. C. F., \& Viana, D. C. (2020). Current status of aquaculture in the world: COVID-19 first impacts. Research, Society and Development, 9(8), e462985798, doi: 10.33448/rsd-v9i8.5798.

Stueland, S., Hatai, K., \& Skaar, I. (2005). Morphological and physiological characteristics of Saprolegnia spp. strains pathogenic to Atlantic salmon, Salmo salar L. Journal of Fish Diseases, 28(8), 445-453.

Tavares-Dias, M., Martins, M. L., \& Moraes, F. R. (2001). Fauna parasitária de peixes oriundos de pesque-pague do município de Franca, São Paulo, Brasil. I. Protozoários. Revista Brasileira de Zoologia, 18(1), 67-79.

Tavechio, W. L. G., Guidelli, G., \& Portz, L. (2018). Alternativas para a prevenção e o controle de patógenos em piscicultura. Boletim do Instituto de Pesca, $35(2), 335-341$

Thatcher, V. E. (1991). Amazon Fish Parasites. Amazoniana, 11(3), 263-572.

Thatcher, V. E. (2006). Amazon fish parasites. Aquatic Biodiversity in Latin America (2a ed.). Sofia, 508p.

Tsai, M. A., Ho, P. Y., Wang, P. C., E, Y. J., Liaw, L. L., \& Chen, S. C. (2012). Development of a multiplex polymerase chain reaction to detect five common Gram-negative bacteria of aquatic animals. Journal of Fish Diseases, 35(7), 489-495. https://doi.org/10.1111/j.1365-2761.2012.01372.x.

Videira, M., Velasco, M., Malcher, C. S., Santos, P., Matos, P., \& Matos, E. (2016). An outbreak of myxozoan parasites in farmed freshwater fish Colossoma macropomum (Cuvier, 1818) (Characidae, Serrasalminae) in the Amazon region, Brazil. Aquaculture Reports, 3, 31-34. https://doi.org/10.1016/j.aqrep.2015.11.004.

Whipps, C. M., Fournie, J. W., Morrison, D. A., Azevedo, C., Matos, E., Thebo, P., \& Kent, M. L. (2012). Phylogeny of fish-infecting Calyptospora species (Apicomplexa: Eimeriorina). Parasitology Research, 111, 1331-1342. https://doi.org/10.1007/s00436-012-2969-8.

Whipps, C. M., Adlard, R. D., Bryant, M. S., Lester, R. J., Findlay, V., \& Kent, M. L. (2003). First report of three Kudoa species from eastern Australia: Kudoa thyrsites from mahimahi (Coryphaena hippurus), Kudoa amamiensis and Kudoa minithyrsites n. sp. from sweeper (Pempherisy psilychnus). Journal of Eukaryotic Microbiology, 50(3), 215-219. https://doi.org/10.1111/j.1550-7408.2003.tb00120.x.

Whittington, R. J., Becker, J. A., \& Dennis, M. M. (2010). Iridovirus infections in finfish - critical review with emphasis on ranaviruses. Journal of Fish Diseases, 33(2), 95-122. https://doi.org/10.1111/j.1365-2761.2009.01110.x.

Ye, Y. W., Fan, T. F., Li, H., Lu, J. F., Jiang, H., Hu, W., \& Jiang, Q. H. (2013). Characterization of Aeromonas hydrophila from hemorrhagic diseased freshwater fishes in Anhui Province, China. International Food Research Journal, 20(3), 1449-1452.

Yong, C. Y., Yeap, S. K., Omar, A. R., \& Tan, W. S. (2017). Advances in the study of nodavirus. PeerJ Computer Science, 5(5), 1-31.

Zietara, M. S., Rokicka, M., Stojanovski S., Skorkowski E. F., \& Lumme J. (2007). Alien mitochondrial DNA in variant clones of Gyrodactylus salaris indicates a complex hybrid history in salmonid farms. 7th International Symposium on Fish Parasites. Parassitologia, 49, 119 